\title{
Valuing coastal recreation and the visual intrusion from commercial activities in Arctic Norway
}

\author{
Margrethe Aanesen, * Jannike Falk-Andersson," Godwin Kofi Vondolia, * Trude Borch, ${ }^{\not}$ \\ Ståle Navrud, ${ }^{\S}$ Dugald Tinch ${ }^{\ddagger}$
}

\begin{abstract}
The coastal zone in the Arctic is being extensively used for recreational activities. Simultaneously, there is an increasing pressure from commercial activities. We present results from a discrete choice experiment implemented in Arctic Norway, revealing how households in this region make trade-offs between recreational activities and commercial developments in the coastal zone. Our results show that, although people prefer stricter regulation of commercial activities, they welcome expansion in marine industries like aquaculture and marine fishing tourism. We also find evidence of high willingness-to-pay for new jobs; and this may partly explain the preferences for the commercial facilities in spite of the visual intrusion they create. On the other hand people expressed a clear dislike for littering of the beaches. Hence, the message to policy makers is to allow for commercial development in the coastal zone, but only under strict regulations, especially related to measures reducing the amount of marine debris.
\end{abstract}

Keywords: Arctic coastal zone, discrete choice experiment, environmental quality, aquaculture, marine fishing tourism, recreation

QEL: Q51, Q57

Corresponding author: * Margrethe Aanesen, UiT-Arctic University of Norway, PO Box 6050 Langnes, 9037 Troms $\varnothing$, Norway, +4791858989, margrethe.aanesen@uit.no

\# Jannike Falk-Andersson, Norut Northern Research institute Troms $\varnothing$, PO Box 6434, 9294 Troms $\varnothing$, Norway, +4741614770, Jannike.falk.andersson@norut.no

* Godwin Kofi Vondolia, UiT-Arctic University of Norway, PO Box 6050 Langnes, 9037 Troms $\varnothing$, Norway, +4777645564, godwin.k.vondolia@uit.no

$\not$ Trude Borch, Akvaplan-Niva, Framsenteret, PO Box 6606 Langnes, 9296 Troms $\varnothing$, Norway, +4797965179 , trude.borch@akvaplan.niva.no

$\S$ Ståle Navrud, Norwegian University of Life Sciences, PO box 5003, 1432 Ås, Norway, +4767231142.

Stale.navrud@nmbu.no

f Dugald Tinch, University of Tasmania, Private bag 84, Hobart TAS 7001, Tasmania, +61 362262999,

dugald.tinch@utas.edu.au 


\section{$1 \quad$ Introduction}

User conflicts in the coastal zone of Norway can be expected to increase as activities such as aquaculture and marine fishing tourism are claiming more space (Jentoft and Buanes, 2005, Hersoug and Johnsen, 2012, Borch, 2009). The need for increased access to space is often justified in terms of the economic importance of these industries. Thus, activities that have no apparent economic value attached to them, such as recreational use, risk being overlooked in decision-making processes. While recreational uses are frequently accounted for in the planning process through hearings, there is often a greater emphasis on commercial considerations as the economic impact is more explicit and easier to quantify (Nilsson et al., 2008, Hanley et al, 2003). However, the conversion to a more holistic and ecosystem-based approach to management, requires consideration of the wider range of ecosystem services provided by the coastal zone. In particular, there is a need for a better understanding of cultural ecosystem services (like recreation)to enable policy makers to include values related to such services in their decision-making. Valuation studies of willingness to pay (WTP) to preserve coastal zone areas for recreation can aid decision makers in securing sustainable use of coastal areas through the development of policies that are both economically efficient and socially acceptable (Fletcher et al., 2014).

The objectives of our study was to identify the public uses the coastline in Arctic Norway for recreation and to elicit public preferences for a range of possible coastal zone management alternatives. Contrary to many other populated coastal areas, Arctic Norway has a long coastline, of which large parts are relatively desolate, whereas others are quite densely populated with a range of users. This difference in population and users requires considered demand analysis, as from a policy perspective any divergence may lead to issues related to appropriate policy implementation. The study applies a stated preference environmental valuation method (Discrete Choice Experiment, DCE) to a random sample of households in Arctic Norway to elicit the relative willingness to pay for various environmental and economic attributes. The DCE aims to provide decision-relevant information for coastal zone management in a region with little scarcity of open space, as opposed to previous SP studies of coastal areas where open space is a scarce resource.

The paper is organised as follows: Section 2 presents the study area and related literature, Section 3 presents data and methodology, Section 4 provides results, including a discussion of main policy implications, and Section 5 concludes.

\section{Background}

\subsection{Study area}


Our study area is the three northernmost counties of Norway; Nordland, Troms and Finnmark. As can be seen in Figure 1 this region of Norway makes up about a third of the land area. The Arctic Circle bisects the region approximately $100 \mathrm{~km}$ south of the city of Bod $\varnothing$.

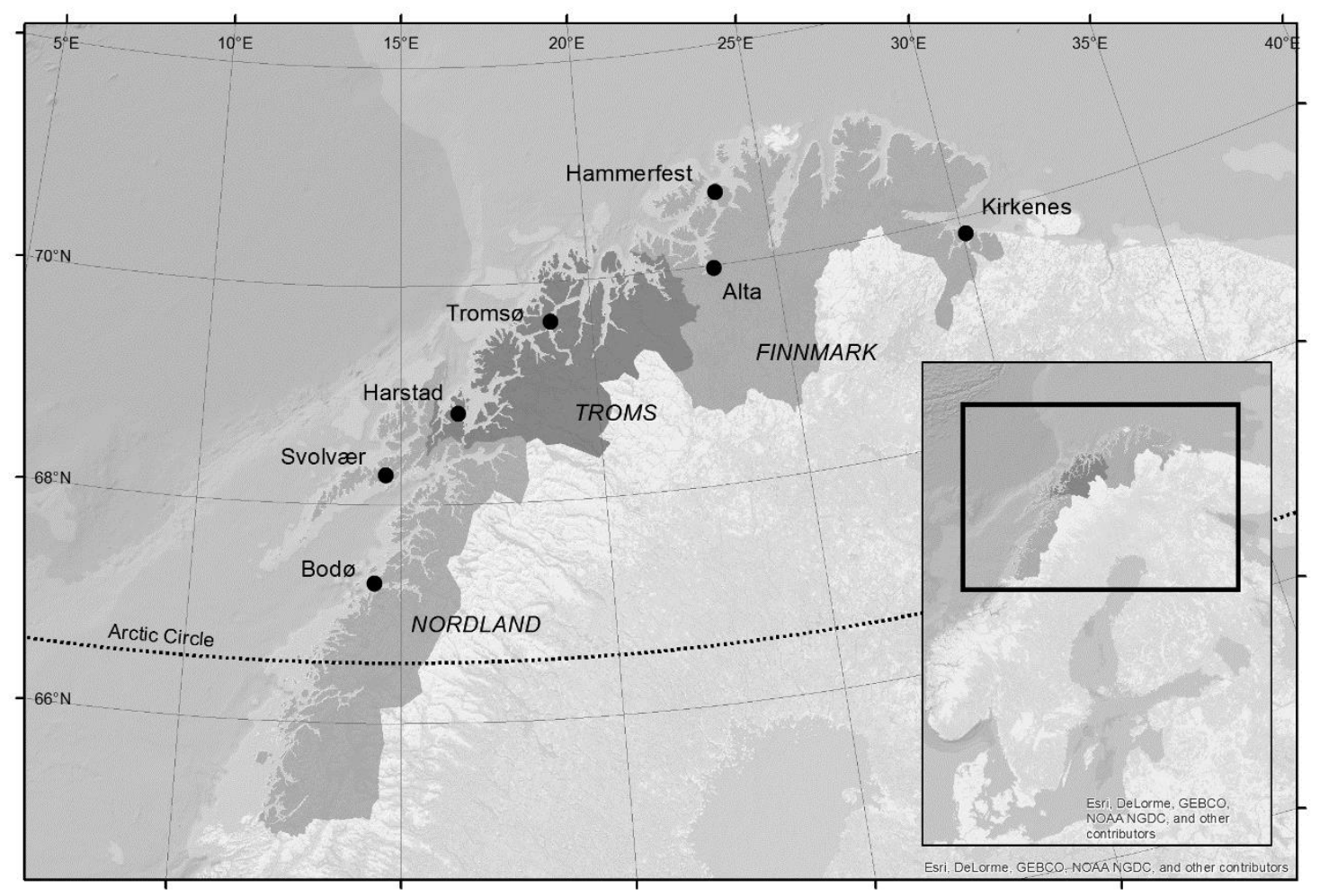

Figure 1 Map of Norway and Arctic Norway

The majority of this area lies north of the Arctic circle and therefore belongs to the Arctic part of mainland Norway, henceforth Arctic Norway. This is a sparsely inhabited area with 490000 inhabitants over $112951 \mathrm{~km}^{2}$. The total territorial waters of Norway are $145,463 \mathrm{~km}^{2}$, and $83,444 \mathrm{~km}^{2}$ of this is located off the coast of Arctic Norway (Kartverket, 2016).

Arctic Norway is topographically and biologically very varied. The coast is characterized by fjords, islands, mountains diving into the sea as well as rivers and lakes with abundant fish resources. We also find islands with bird cliffs fringed by narrow flat beaches and sand dunes. The marine ecosystem along the coast of Arctic Norway and into the Barents Sea is characterized as "a varied coastal ecosystem." The warm, nutrient rich water coming from the Atlantic makes up the basis for the abundant marine production supporting rich fisheries, in addition to numerous species of sea birds, whale and seal in the area (van der Meeren, 2009). These natural resources make the foundation for an important outdoor recreational culture in the region. 
Fisheries and small-scale agriculture have historically been the most important economic activities in Arctic Norway. However, the area has become more economically diverse and industries such as aquaculture and tourism are developing. There are also plans for increased petroleum and mining/mineral activity in the region, but presently there are few people employed in these industries. For aquaculture, it is important to note that of 1060 aquaculture licences in production in Norway in 2015 only 380 are located in Arctic Norway (Directorate for Fisheries, 2016). Without taking into consideration the suitability of territorial waters for aquaculture, this implies that for each fish farm in Arctic Norway there are $219 \mathrm{~km}^{2}$ of territorial waters available, compared to $91 \mathrm{~km}^{2}$ for the rest of Norway. Hence, the density of fish farms is comparatively far lower than in other parts of the Norwegian coast.

Focus groups, run to develop the survey, identified that most people living in this part of Norway make use of the coastal zone (CZ) for recreational purposes. Based on input from the focus groups, the coastal zone was defined as "an area with proximity to or a view towards the sea, on the landside a maximum of $3 \mathrm{~km}$ from the littoral zone, and on the seaside defined by the baseline". Focus group participants also revealed that there is a broad understanding that commercial activities should have access to the $\mathrm{CZ}$ in order to generate economic wealth and jobs.

\subsection{Existing literature}

The existing literature on WTP for access to the $\mathrm{CZ}$ is huge, but focuses mainly on specific recreational activities. Surveys of recreational fishing, swimming and diving are the most numerous ${ }^{1}$. Often, the demand for a particular site (or sites) with specific characteristics is estimated (Freeman et al., 2014, chap. 9), and attempts have been made to simultaneously estimate the demand for a series of recreational sites in order to reveal substitution effects (Scarpa and Thiene, 2003). The majority of these studies focus on revealed preference methodologies where economic value is identified based upon actual behaviour. However, these methods can only identify values for attributes which are present. Our analysis takes place on an aggregate, as opposed to site-specific, level, and looks at the general CZ in Arctic Norway. Our focus has been on mapping the extent and diversity of recreational activities performed by inhabitants and using this as an interaction variable when estimating preferences for environmental and economic variables. Our analysis includes a Discrete Choice Experiment (DCE). One issue with this methodology is that attribute levels and payments are hypothetical. However, respondents were informed that outcomes of the research would be made available to policy makers, which incentivises accurate statements of willingness to pay. Also, the structure of the DCE is such that trade-offs between attributes occur, so the relative rankings of attributes will hold even if confidence in the actual willingness to pay

\footnotetext{
${ }^{1}$ For a selection of articles, see e.g. Navrud, 1992, Hanley et al., 2003, Rosenberger et al., 2016.
} 
estimates is of concern to policy makers (Hanley and Barbier, 2009). Additionally, there are indications that the more familiar respondents are with a good, the lower hypothetical bias is (Schlapfer and Fischhoff, 2012). We started the survey by asking which recreational activities people perform along the coast, how often they perform them, and in which locations. In this way, prior to the hypothetical trade-offs of the DCE, the respondents are familiarised with the context and the good to be valued.

Blamey et al. (1996) and Blamey et al. (2000) showed that people generally have preferences for both environmental and economic factors. Downplaying or omitting the economic factors will not only lead some respondents to perceive a study as biased, but also results in the elicitation of a blurred construct (Blamey et al., 2000, p.277). The two economic factors most widely used in non-market valuation surveys are jobs and regional income generation. People may not only have preferences for their own job or job opportunities, they may also derive satisfaction from knowing about the existence of jobs (Morrison et al., 1999), a concept often referred to as the non-use value of employment (Bennett and Blamey, 2001). In a Contingent Valuation survey, Lockwood et al. (1994) found that on average $29 \%$ of stated WTP to an NGO-administered trust fund in Australia could be attributed to "increased job security for timber workers". Morrison et al. (1999) used a DCE to derive the non-use environmental values provided by a major wetland in Australia as well as estimates on the non-use values the community placed on preventing loss of jobs. While both the environmental attributes and the job attribute were significant in explaining the choices made, people were willing to pay AUS $\$ 0.13$ for one extra job, versus AUS \$4 for the presence of an additional endangered species in the wetlands. Mallawaarachchi et al (2001) used regional income generation combined with two environmental attributes in a study valuing protection of natural vegetation in an area suitable for cane production. They show that the WTP to secure regional income generation is below AUS \$1 per million AUS dollars of income, while the WTP for protecting woodlands and wetlands is AUS \$2.56 per 1000 hectares and AUS \$39.95 per hectare respectively. Blamey et al. (2000) emphasize a balance between environmental and economic attributes, and in two DCE surveys to value remnant vegetation in a desert area in Australia, they applied two economic and two environmental attributes.

Aquaculture and marine fishing tourism are steadily increasing in Norway, and the growth is highest in Arctic Norway. The growth in both industries has been met with protest from commercial fisheries as well as other stakeholders (Borch 2009, Borch, 2010, Brattland et al, 2016). There is some Norwegian skepticism regarding foreign access to the coastal area and fish stocks, as well as regarding the trend of "catch \& release" fishing (Ferter et al. 2013). In spite of these conflicts, there are only a few studies of the fishing tourism sector, and these studies are limited to the more professional part of the industry and little on the less organized fishing tourism. Vølstad et al. (2011) studied the fish landings from tourist anglers associated with 445 enterprises, and Borch et al. (2011) studied the economic impact of marine tourism fishing tourism in these enterprises. These studies do not include the less organized, recreational sector. The private rentals of accommodation facilities and boats 
through this sector seem to create the most important conflicts in the CZ in Arctic Norway. Regarding aquaculture, Abate et al (2017) discuss various outcomes of public aquaculture management with nonbenevolent managers, showing that higher relative power of a pro-industry agency compared to a proenvironment agency leads to higher growth than is socially optimal, and vice versa. Extrapolating the results of Abate et al (2017) one could hypothesize that input from a broader set of stakeholders will lead to more efficient management outcomes. Further, Primevera (2006) and Whitmarsh and Wattage (2006) discuss how the spread of parasites and disease, misuse of chemicals, and the release of litter impact coastal areas and affect public opinion of the aquaculture industry.

\section{Data and methods}

\subsection{Formulation of survey}

To inform the development of the survey we organized six focus groups in three municipalities in Arctic Norway; four with general citizens, representing themselves, and two with political representatives and representatives from various industries and NGOs. The topics discussed in these groups were: recreational activities in the CZ throughout the year, possible future changes in the use of the $\mathrm{CZ}$ and the limitations or possibilities following any change of use. We also got feedback on possible payment vehicles and concluded that a fee to access nature or to harvest marine fish was found unacceptable by respondents as free access to these are ingrained in the Norwegian culture. Feedback from the focus groups with citizens informed us about; how to formulate questions on recreational activities in the $\mathrm{CZ}$, the appropriate definition of the $\mathrm{CZ}$, and opinions on commercial versus private recreational use. All focus group participants identified aquaculture and tourism as important industries, but underlined the need for regulations to limit negative environmental effects and crowding. In Norway, as in other countries, the awareness around marine litter is increasing. Beach cleaning has become popular and is regularly implemented in many municipalities in Arctic Norway. Widespread knowledge of, and experience with, litter on the beaches among the focus group participants indicated that this would serve as a representative environmental attribute. Recreational fishing is among the most common spare time activities in Norway (Våge, 2009), which was confirmed by the focus groups. Thus, recreational fish catch was selected as the second environmental attribute. Interviews with representatives from the three county administrations in Arctic Norway in charge of commercial development confirmed that aquaculture and marine fishing tourism were the two coastal industries expected to expand during the next decade in all three counties. Hence, we chose to use increase in these industries along the coastline as one economic attribute. An increase in marine industries is represented by a change in the scenic view of the coast. The other economic attribute adopted is the number of new jobs created in Arctic Norway. 
In the choice cards, the business-as-usual (BAU) alternative was formulated as a deterioration of the environmental quality of the $\mathrm{CZ}$ due to increased commercial activity. Without stricter regulations, we hypothesized increased commercial activities in the $\mathrm{CZ}$, causing the visual intrusion of fish farms and tourism facilities along the coast, the creation of new jobs, more beach litter and a reduction in recreational fish catches. Alternatively, authorities may implement stricter regulation of commercial activities in the CZ. This could lead to less new jobs and commercial facilities. However, it may also imply less litter on the beaches and a lower reduction, if any, in recreational fish catches. Stricter regulations, however, comes at a cost for local inhabitants, formulated as an increase in local taxes. Table 1 yields an overview of attributes and the levels they take. All surveys and focus groups were conducted in Norwegian. A translated example of a choice card is given in the appendix.

\begin{tabular}{|c|c|c|c|c|c|}
\hline ATTRIBUTE & BAU LEVEL & LEVEL 1 & LEVEL 2 & LEVEL 3 & LEVEL 4 \\
\hline $\begin{array}{l}\text { INDUSTRIAL } \\
\text { IMPACT ON } \\
\text { VIEWS }\end{array}$ & $\begin{array}{l}\text { Aquaculture and } \\
\text { marine fishing } \\
\text { tourism }\end{array}$ & Only aquaculture & $\begin{array}{l}\text { Only marine } \\
\text { fishing tourism }\end{array}$ & & \\
\hline LITTER & $\begin{array}{l}\text { Litter will increase } \\
\text { by } 50 \% \text { compared } \\
\text { to the present } \\
\text { situation }\end{array}$ & $\begin{array}{l}\text { Litter will increase } \\
\text { by } 25 \% \text { compared } \\
\text { to the present } \\
\text { situation }\end{array}$ & $\begin{array}{l}\text { There will be no } \\
\text { increase in litter }\end{array}$ & & \\
\hline $\begin{array}{l}\text { RECREATIONAL } \\
\text { CATCHES }\end{array}$ & $\begin{array}{l}\text { Daily catches (15 } \\
\mathrm{kg} \text { ) from } \\
\text { recreational boat } \\
\text { fishing reduced by } \\
5 \mathrm{~kg}\end{array}$ & $\begin{array}{l}\text { Daily catches ( } 15 \\
\mathrm{~kg} \text { ) from } \\
\text { recreational boat } \\
\text { fishing reduced } \\
\text { by } 2 \mathrm{~kg}\end{array}$ & $\begin{array}{l}\text { Daily catches (15 } \\
\mathrm{kg} \text { ) from } \\
\text { recreational boat } \\
\text { fishing will not be } \\
\text { reduced }\end{array}$ & & \\
\hline NEW JOBS & $\begin{array}{l}500 \text { new jobs in } \\
\text { Arctic Norway }\end{array}$ & $\begin{array}{l}350 \text { new jobs in } \\
\text { Arctic Norway }\end{array}$ & $\begin{array}{l}250 \text { new jobs in } \\
\text { Arctic Norway }\end{array}$ & $\begin{array}{l}100 \text { new } \\
\text { jobs in Arctic } \\
\text { Norway }\end{array}$ & \\
\hline COSTS NOK & 0 & 500 & 1000 & 2000 & 3000 \\
\hline
\end{tabular}

Table 1 Attributes and attribute levels

Before piloting, we tested the survey in two new focus groups; one group with university employees with a mix of disciplinary backgrounds, and one with bachelor students in interdisciplinary marine sciences. These groups emphasized the need to define "the coast" and "coastal recreation". In response, we defined the coast as "an area with proximity to or a view towards the sea, maximum $3 \mathrm{~km}$ from the littoral zone". Following this second round of focus groups, we also made changes in the visual presentation of the choice cards, and tested the new version on five individuals who were asked to think aloud when filling in the survey. This test did not result in any changes to the survey. We ran the pilot study in August 2015 with 100 respondents. We presented 8 choice cards to each respondent. Efficient designs with zero priors were used to generate the design for the pilot survey (i.e. the combinations in which attributes are offered in each choice task). The parameter estimates from the pilot survey then served as priors in the generation of efficient design in the main survey. Both designs were generated 
using Ngene (ChoiceMetrics, 2014). Based on the pilot results we changed the design of the choice cards, and in early September 2015 we distributed the main survey to an internet panel of 1109 people living in Arctic Norway. The survey was open for one month, and by the closing date, 518 responses were received, a response rate of $47 \%$. The pilot respondents are not included in the sample.

\subsection{Econometric model}

Random utility theory suggests that the utility a person receives from a good can be divided into a determined part, which can be explained by the researcher, and a random part (McFadden, 1974). The utility to person $n$ of choosing alternative $j$ in choice situation $t$ is thus given by;

$U_{n j t}=b * X_{n j t}+e_{n j t}$

where $X_{n j t}$ is a vector of attributes specifying the good, $b$ is a vector of estimated coefficients for the attributes, and $e_{n j t}$ is an independently and identically distributed (IID) extreme value (usually Gumbel) distributed error term.

It is reasonable to assume that respondents differ in their preferences for the attributes. Formally, we take preference heterogeneity into consideration by letting the vector of attribute coefficients, $\boldsymbol{b}$, be respondent dependent, i.e. $\boldsymbol{b}_{\boldsymbol{n}}$, with a distribution specified by the researcher (Hensher et al., 2007). Hence,

$b_{n}=b+L \mu$

where $\boldsymbol{b}$ is the mean estimated coefficient for the specified attribute, $\mathrm{L}$ is a lower-triangular Choleski factor of $\mathrm{V}$, the covariance matrix, and $\mu$ is a vector of independent standard normal deviates. Thus, (2) is now given by $U_{n j t}^{*}=b_{n} * X_{n j t}+e_{n j t}$

While the model given by (1) is the multinomial logit model (MNL), the model given by (3) is the mixed MNL model.

When given a series of alternatives, described by the levels of the attributes, $X$, a person will more likely choose alternative $j$ to alternative $k$ when $U_{n j t}>U_{n k t}$. Given the stochastic nature of the utility function, the probability that respondent $n$ will choose alternative $j$ in choice situation $t$ is;

$P_{n j t}=\operatorname{Pr}\left(b_{n} * X_{n j t}+e_{n j t}>b_{n} * X_{n k t}+e_{n k t}, \quad \forall j \neq k\right)$ 
With IID extreme value error terms, (4) reduces to the following expression for conditional choice probability for choosing one specific alternative (Train, 2009, p 36)

$P_{n j t}=\frac{\exp ^{\left(b_{n} * X n j t\right)}}{\sum_{k} \exp ^{\left(b_{n} * X n k t\right)}}$

Taking the product of (5) over all choice situations yields the expression for the probability of respondent $n$ 's observed sequence of choices. The integral of this sequence yields the unconditional probability of observing a sequence of choices. This integral cannot be calculated analytically and is instead approximated by a summation over randomly chosen values of $\boldsymbol{b}$. The average of the resulting probabilities is taken as the approximate (simulated) choice probability;

$P_{n}^{S}(\theta)=\frac{1}{D} \sum_{d=1}^{D}\left[\int\left(\prod_{t=1}^{T} P_{n j t}\right) f\left(b \mid \theta^{*}\right) d b\right]$

where $D$ is the number of draws from the specified distribution, $f(\bullet)$ is the density function of the distribution and $\theta$ the distribution parameters. The simulated log-likelihood function is constructed as $\operatorname{SSL}(\theta)=\sum_{n=1}^{N} P_{n}^{S}(\theta)$, where $N$ is the total number of respondents. The estimated parameters are those which maximize the simulated log-likelihood function.

The variance of extreme value distributed error terms in a logit model is given by $\operatorname{var}\left(e_{n j t}\right)=\sigma^{2}\left(\frac{\pi^{2}}{6}\right)$, where $\sigma$ is the scale of utility (Train, 2009). When error terms are IID, normalization of utility for scale is straightforward, and in a standard logit model the error variance is usually normalised to $\frac{\pi^{2}}{6}$. In this case, $U_{n j t}^{* *}=\frac{b_{n}}{\sigma} * X_{n j t}+e_{n j t}^{*}$, and the new coefficients reflects the effects of the observed variable relative to the standard deviation of the unobserved factors. Note that with IID error terms, such a normalization does not have any impact on the relative importance of the attributes. If we suspect different segments of the dataset to have different scale, we can normalise the variance for one segment and then estimate the scale for each segment relative to the first segment. Estimating relative scales enables us to distinguish between preference weights and scale across the segments.

The estimated vector of parameters, $\widetilde{b_{n}}$, is expressed in utility units. Estimation of willingness to pay (WTP) is essential in our model, and therefore we keep the cost-attribute parameter fixed. This means that the distribution of the WTP is simply the scaled distribution of the non-cost attribute parameters. The distribution of the WTP is far more complex when the cost-attribute parameter varies as well (Train, 2009, p. 309). In order to derive willingness-to-pay (WTP) in monetary units we take the ratio of each of the non-cost attribute coefficients and the 
cost-attribute coefficient. Calculating marginal WTPs under mixed MNL with non-random cost attribute, there is no need to take into account coefficient correlations. Hence, the marginal unconditional willingness to pay for an attribute is given by;

$W T P_{h}=\frac{\breve{b}_{h}}{b_{c}}, \forall h \neq c$

where $\breve{b}_{h}=\frac{1}{R} \sum_{r=1}^{R} b_{h}$ is the average of R draws from the distribution of the estimated coefficient for attribute $h$, and $b_{c}$ is the cost attribute coefficient. The draws were taken using the mean marginal WTP and its standard deviation which are computed as $\frac{b_{h m}}{b_{c}}$ and $\frac{b_{h s}}{b_{c}}$ where $b_{h m}$ and $b_{h s}$ are the mean and standard deviation coefficient respectively and are both scaled by the scale parameter.

\section{$4 \quad$ Survey results}

\subsection{Results of socio-economic and psychological scaling survey elements}

Compared to the population of our study region, the sample is somewhat older, more highly educated, and earned somewhat more. Of the sample $45 \%$ were male, below the population average of $51.5 \%$. About $40 \%$ of the respondents are 50-67 years old in the sample, compared to $29 \%$ in the population. Respectively, respondents in age groups $18-30$ and $31-50$ constitute $14 \%$ and $27 \%$ respectively in the sample, compared to $23 \%$ and $34 \%$ in the population. Almost $60 \%$ of the sample has university-level education, and this is higher than the regional average of $28 \%$. Finally, a larger proportion (43\%) of the households in the sample has an annual income in the range of NOK 600 k-999k (USD $62,000-103,000)^{2}$ compared to $32 \%$ of the population, whereas a smaller proportion of $26.7 \%$ earn between NOK 200k-600k (USD 21,000-62,000) compared to 40\% of the region's population. Households earning below 200k NOK (USD 21,000) and above $1 \mathrm{~m}$ NOK (USD 103,000) are proportionally the same in the sample and the population. About $18 \%$ of the sample said they were members of recreational organizations, only $6 \%$ of the sample said they were members of environmental organizations.

Table A1 in the appendix shows the average number of times respondents stated they engaged in selected recreational activities during summer and winter respectively. Of the 518 respondents, $84 \%$ had walked on the beach and $67 \%$ had barbequed at least once during the summer season (May-October). For other activities, the numbers are lower, although $53 \%$ said they had taken boat trips and $48 \%$ had been fishing at least once. Only 25 people, i.e. $5 \%$ of the sample, state they did not take part in any recreational activity in the $\mathrm{CZ}$ during summer. During the winter season, activity levels were lower.

\footnotetext{
2 The PPP exchange rate between USD and NOK in 2015 was on average 9.682.
} 
When asked to assess the amount of beach litter and the environmental quality of a CZ location where they currently perform recreational activities, the respondents were quite happy with the conditions. Using a Likert scale were 1 indicates little litter and high environmental quality and 6 indicates much litter and low environmental quality, the majority of the respondents rated these areas between 1 and 3 . As Table 2 shows, 57\% find relatively little litter on the beaches they prefer to use, and 68\% think these beaches have high or relatively high environmental quality.

\begin{tabular}{l|llllllll}
\multicolumn{1}{l}{} & $\mathbf{1}$ & $\mathbf{2}$ & $\mathbf{3}$ & $\mathbf{4}$ & $\mathbf{5}$ & $\mathbf{6}$ & $\mathbf{7}$ & $\mathbf{N}$ \\
\hline $\begin{array}{l}\text { AMOUNT OF } \\
\begin{array}{l}\text { LITTER } \\
\text { ENVIRONMENTAL } \\
\text { QUALITY }\end{array}\end{array}$ & 5.5 & 27 & 24.5 & 18 & 15 & 4.5 & 5.5 & 518 \\
& 16 & 26 & 26 & 22 & 4.5 & 1 & 4.5 & 518
\end{tabular}

Table 2 Percentage of responses on the Likert scale representing level of litter and environmental quality, 1=low level of litter/good environmental quality, 6=high level of litter/low environmental quality, 7=don't know.

Finally, we elicited the respondents' attitudes to recreational versus commercial use of the CZ through a Likert scale where 1 indicates strongly agree while 6 indicates strongly disagree. The results are given in Table 3.

Respondents tend to disagree with statements prioritising commercial use over recreational use and vice-versa. Also noteworthy is that while respondents were highly likely to agree with the statement that the aquaculture industry is a threat to wild salmon stocks, there is more of a division of opinion regarding whether marine tourism fishing reduces local fish stocks.

\begin{tabular}{|c|c|c|c|c|c|c|c|c|}
\hline & $\begin{array}{l}1 \\
\text { (STRONGLY } \\
\text { AGREE) }\end{array}$ & 2 & 3 & 4 & 5 & $\begin{array}{l}6 \\
\text { (STRONGLY } \\
\text { DISAGREE) }\end{array}$ & $\begin{array}{l}7 \\
\text { (DON'T } \\
\text { KNOW) }\end{array}$ & $\mathbf{N}$ \\
\hline $\begin{array}{l}\text { One should not } \\
\text { encourage use of } \\
\text { the } C Z \text { for } \\
\text { commercial } \\
\text { activities }\end{array}$ & 2 & 4 & 18 & 30 & 24 & 16 & 6 & 516 \\
\hline $\begin{array}{l}\text { Recreational use } \\
\text { should be less } \\
\text { emphasised than } \\
\text { commercial } \\
\text { interests in the CZ }\end{array}$ & 3 & 7 & 20 & 29 & 22 & 13 & 6 & 517 \\
\hline $\begin{array}{l}\text { Industry should pay } \\
\text { for the } \\
\text { environmental }\end{array}$ & 37 & 34 & 19 & 5 & 1 & 1 & 3 & 517 \\
\hline
\end{tabular}




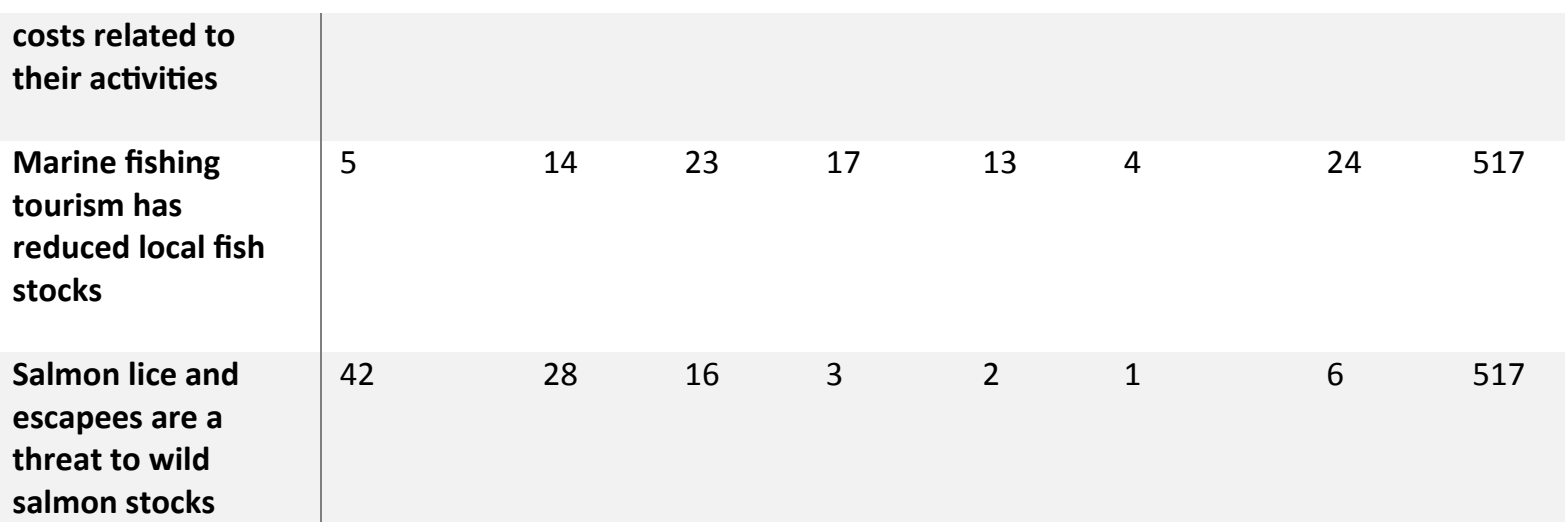

Table 3 Percentage of responses on the Likert Scale indicating agreement or disagreement with the given statements.

\subsection{Main results of stated preference elements}

The dataset exhibits some degree of preference heterogeneity, leading us to apply a mixed multinomial logit (MNL) model in the estimations. A likelihood ratio test rejected heteroskedasticity.

The attribute "industrial impacts on views" indicates to what degree commercial facilities would be visible along the coast. The design of this attribute enables us to elicit two types of preferences; i) preferences for the physical distribution of commercial activities, ii) preferences for specific types of commercial activities, i.e. aquaculture and/or fishing tourism. In order to disentangle the two types of preferences we set up three models, which only differ in the treatment of the "industrial impact on views" attribute. Model 1 elicits preferences for the distribution of commercial activities, independent of type of industry. In this model, the industrial visual impact variable equals 1 if both aquaculture and fishing tourism can be observed along the coast and 0 if only one of the industries can be observed. A positive model estimate would indicate that people prefer to have both industries present to only one. In model 2, we distinguish between the two industries by dividing the "industrial impact on views" attribute into two dummies; one for aquaculture and one for fishing tourism. The former takes the value 1 if only fish farms can be observed along the coast and 0 if both types of industries can be observed. The latter takes the value 1 if only tourism facilities can be observed along the coast and 0 if both industries can be observed. If both variables have a positive and significant mean coefficient it would indicate that people prefer the presence of less industrial activity, and that they do not prefer any of the two industries. If for example the former variable has a positive mean parameter and the latter a negative mean parameter, and both are significant, it would indicate that people prefer to see fish farms to tourism facilities. Finally, in model 3 , we reverse the two industrial visual impact variables of model 2 , such that the aquaculture variable equals 1 if fish farms can be seen, either alone or together with tourism facilities, and 0 if fish farms cannot be seen. The fishing tourism variable equals 1 if tourism facilities can be seen, either alone or with fish farms. A positive and significant 
mean coefficient for the aquaculture variable and a negative and significant coefficient for the fishing tourism variable would indicate that people prefer seeing fish farms to seeing tourism facilities.

The models were estimated in $\mathrm{R}(\mathrm{CMC}, 2017)$, and the simulations were based on 500 Halton draws. The job and litter attribute levels were divided by 100 , and the levels of the cost attribute divided by 1000 . Thus, the coefficients estimated for these variables are to be interpreted as a marginal change in preferences for every 100 new jobs, for $100 \%$ increase in litter, and for an additional 1000 NOK (approximately \$103 USD). The coefficient estimated for recreational catches is the marginal chance in preferences for one $\mathrm{kg}$ decrease in recreational catch. Although one could argue that positive preferences for increase in litter and negative preferences for new jobs are unreasonable, we allow such "unexpected" preferences and assume normal distribution for the non-cost attribute parameters. There is a high chance of attribute correlation, especially for "industrial impact on views" and "new jobs". To allow for this, as well as other less obvious correlations, we assume correlation across all random variables. Table 4 shows the estimation results for the three models.

\begin{tabular}{|c|c|c|c|}
\hline & Model 1 & Model 2 & Model 3 \\
\hline ASC BAU & $-1.17(0.11)^{* * *}$ & $-1.25(0.11)^{* * *}$ & $-0.88(0.13)^{* * *}$ \\
\hline IVI:both-mean & $0.20(0.07) * * *$ & & \\
\hline IVI:aqua-mean & & $-0.13(0.10)$ & $0.12(0.41)$ \\
\hline IVI:tourism-mean & & $-0.18(0.08) * *$ & $-0.04(0.20)$ \\
\hline Litter - mean & $-0.92(0.3)^{* * *}$ & $-1.1(0.38)^{* * *}$ & $-1.29(0.33)^{* * *}$ \\
\hline Recr.catches - mean & $0.15(0.02)^{* * *}$ & $0.13(0.03) * * *$ & $0.08(0.02)^{* * *}$ \\
\hline New jobs - mean & $0.17(0.03)^{* * *}$ & $0.15(0.03) * * *$ & $0.11(0.03)^{* * *}$ \\
\hline Cost - mean & $-0.35(0.03)^{* * *}$ & $-0.44(0.04)^{* * *}$ & $-0.39(0.04)^{* * *}$ \\
\hline IVI:both - st.dev & $0.98(0.09)^{* * *}$ & & \\
\hline IVI:aqua - st.dev & & $-1.48(0.14)^{* * *}$ & $2.63(0.32)^{* * *}$ \\
\hline IVI:tourism - st.dev & & $-0.41(0.11)^{* * *}$ & $0.26(1.31)$ \\
\hline Litter - st.dev & $1.80(0.44)^{* * *}$ & $-2.35(0.54)^{* * *}$ & $-1.67(0.43) * * *$ \\
\hline Recr.catches - st.dev & $-0.04(0.08)$ & $-0.04(0.05)$ & $0.03(0.02)$ \\
\hline New jobs - st.dev & $-0.01(0.04)$ & $0.01(0.06)$ & $-0.02(0.03)$ \\
\hline $\begin{array}{l}\text { SV:aqua-SV:tourism- } \\
\text { corr }\end{array}$ & & $-0.27(0.13)^{* *}$ & $2.21(0.18)^{* * *}$ \\
\hline IVI:both-litter-corr & $4.72(0.44)^{* * *}$ & & \\
\hline IVI:aqua-litter-corr & & $6.26(0.69)^{* * *}$ & $4.35(0.58)^{* * *}$ \\
\hline SV:tourism-litter-corr & & $0.12(0.58)$ & $1.97(2.64)$ \\
\hline IVI:both-harv-corr & $0.32(0.03)^{* * *}$ & & \\
\hline IVI:aqua-harv-corr & & $0.34(0.04)^{* * *}$ & $0.22(0.03)^{* * *}$ \\
\hline IVI:tourism-harv-corr & & $0.15(0.04)^{* * *}$ & $-0.01(0.08)$ \\
\hline IVI:both-job-corr & $0.42(0.03)^{* * *}$ & & \\
\hline IVI:aqua-job-corr & & $0.27(0.03)^{* * *}$ & $0.47(0.05)^{* * *}$ \\
\hline IVI:tourism-job-corr & & $0.20(0.05)^{* * *}$ & $0.03(0.09)$ \\
\hline $\begin{array}{l}\text { litter-recr.catches- } \\
\text { corr }\end{array}$ & $-0.06(0.05)$ & $0.06(0.05)$ & $0.01(0.03)$ \\
\hline Litter-job-corr & $-0.04(0.05)$ & $0.07(0.04)^{*}$ & $0.02(0.04)$ \\
\hline Recr.catches-job-corr & $-0.04(0.06)$ & $0.10(0.05)^{* *}$ & $0.01(0.04)$ \\
\hline LL-value & -3268 & -3238 & -3195 \\
\hline
\end{tabular}



"business as usual" (BAU) alternative, IVI= industrial impact on views, IVI:both= both types of industry are visible, IVI:aqua= fish farms are visible alone (model 2) or with tourism facilities (model 3), IVI:tourism= tourism facilities are visible either alone (model 2) or with fish farms (model3). Standard errors for all estimates are given in parentheses.

Table 4 Mean attribute parameters, standard deviations and correlations for models 1-3

The cost attribute is significant and negative in all models. This indicates that respondents are behaving economically rationally, selecting lower amounts associated with any changes they prefer over the BAU baseline levels. In model 1 , the mean parameter is significant for all attributes, whereas the standard deviation is significant only for the "industrial impact on views" and "litter" attributes. The significance in standard deviation indicates that preferences regarding fish catches and jobs are more homogenous than preferences for litter and the industrial impact on view. The final section of the Table shows the lower-triangular Cholesky-matrix. The estimated coefficients indicate that while the "industrial impact on views" attribute is correlated with the "litter", "recreational catches" and "new jobs" attributes, the three latter attributes are not correlated with each other.

In model 2, the mean parameter is significant for all attributes except the "industrial impact on views" attribute (IVI:aqua, which indicates whether people prefer to see only fish farms or both fish farms and tourism facilities).Participants are thus indifferent to whether they see only fish farms or whether they see both industries. The negative sign of the "industrial impact on views" attribute (IVI:tourism, which indicates whether people prefer to see only tourism facilities or both tourism facilities and fish farms) shows that people prefer to see both industries. Taken together, these results indicate that people have stronger preferences for the presence of fish farms than for tourism facilities. As in model 1, the estimates for the attributes "recreational catches" and "new jobs" do not have significant standard deviations. While IVI:aqua is correlated with all other attributes, IVI:tourism is not correlated with the "litter" attribute.

In model 3 neither of the "industrial impact on views" attributes are significant. The standard deviation of the "industrial impact on views" attribute IVI:tourism, indicating whether people prefer to see both tourism facilities and fish farms or only tourism facilities, is not significant, and IVI:tourism is only correlated with the other "industrial impact on views" attribute, IVI:aqua. IVI:aqua indicates whether people prefer to see both fish farms and tourism facilities or only fish farms, and this variable exhibits significant preference heterogeneity among respondents, and is correlated with all the other attributes.

\subsection{Willingness-to-pay estimates}


To make the model results from Table 4 more relevant for policy makers, we use the mean and standard deviation estimates to compute marginal unconditional willingness to pay (WTP) measured in USD. Firstly, the distributions for marginal WTPs were computed by dividing both the mean and standard deviation estimates by the estimate of the cost attribute (fixed). Secondly, 1000 draws were taken from the distributions. Finally, the results presented in Table 5 were computed using these draws.

\begin{tabular}{|l|l|l|l|l|l|l|}
\hline & \multicolumn{2}{|l|}{ MODEL 1 } & \multicolumn{2}{l|}{ MODEL 2 } & \multicolumn{2}{l|}{ MODEL 3 } \\
\hline ATTRIBUTE & WTP & $95 \% \mathrm{Cl}$ & WTP & $95 \% \mathrm{Cl}$ & WTP & $95 \% \mathrm{Cl}$ \\
\hline BOTH INDUSTRIES & 83.7 & $(65.6,101.6)$ & & & & \\
\hline ONLY AQUACULTURE & & & -32.2 & $(-53.9,-10.6)$ & & \\
\hline ONLY MARINE FISHING TOURISM & & & -38.7 & $(-44.7,-32.7)$ & & \\
\hline AQUACULTURE PRESENT & & & & & 61.1 & $(18.1,104.3)$ \\
\hline MARINE FISHING TOURISM PRESENT & & & & & -9.9 & $(-14.5,-5.5)$ \\
\hline LITTER & -132.2 & $(-148.9,-120.8)$ & -123.1 & $(-140.3,-106.0)$ & -167.5 & $(-181.0,-154.0)$ \\
\hline RECREATIONAL CATCHES & 217.4 & $(213.8,221.5)$ & 155.4 & $(152.9,158.0)$ & 99.7 & $(97.1,102.8)$ \\
\hline NEW JOBS & 252.5 & $(251.5,253.1)$ & 177.6 & $(177.1,178.2)$ & 140.0 & $(137.9,141.5)$ \\
\hline
\end{tabular}

$\mathrm{Cl}=$ confidence interval

Table 5 Mean unconditional marginal WTP and 95\% confidence intervals for the mean for each attribute, USD, 1000 draws, all estimates significant at 1\% level.

The marginal WTP for litter expresses the change in utility from a 50\% increase in litter. The WTP is negative, indicating disutility associated with litter. The absolute value of this WTP, between 123.1 USD (model 2) and 167.5 USD (model 3), is on the average WTP to avoid a 50\% increase in litter on beaches. The WTP for 500 new jobs is between 252.5 USD (model 1) and 140 USD (model 3) per household, so between 0.3 and 0.5 USD per household per job. The WTP for a $1 \mathrm{~kg}$ reduction in mean catches by recreational fishing, lies between 217.4 USD (model 1) and 99.7 USD (model 3). The "industrial impact on views" attribute for both industries in model 1, which shows WTP for both industries being present along the coast, regardless of which industry, amounts to 83.7 USD. The negative marginal WTP for both "industrial impact on views" attributes in model 2 (i.e. "only aquaculture" and "only tourism") indicate a disutility if only one industry is present. Participants are willing to pay 32.2 USD to see tourism facilities in addition to fish farms, and 38.7 USD to see fish farms in addition to tourism facilities. The "industrial impact on views" attributes in model 3 indicate that participants are willing to pay 61.1 USD to ensure the presence of fish farms, while they are not willing pay anything to ensure the presence of tourism facilities. While the confidence intervals $(\mathrm{Cl})$ are very small for the "job" and "recreational catches" attributes, they are relatively high for the four "industrial impact on views" attributes (i.e. "both industries", "only aquaculture", "only fishing tourism", "aquaculture present and fishing tourism present"). Litter also has a relatively large $\mathrm{Cl}$ compared 
to jobs and recreational catches. This supports the results in Table 4; the positive preferences for new jobs and for reductions in recreational catches are relatively homogenous across the respondents, whereas the preferences for seeing commercial activities, be it fish farms or fishing tourism facilities, are far more heterogeneous. Respondents also display a greater degree of heterogeneity related to litter on the beaches than to new jobs.

In terms of recreational fish catches, a reduction in catches was expected to have a negative impact on utility. However, the estimated mean parameter of this attribute was found to be positive. This indicates that people prefer higher reductions in recreational catches to lower, which we found puzzling. To look further into this finding, we implemented a small follow-up survey with about 30 respondents in the Lofoten Islands, asking for their interpretation of the "recreational fish catches" attribute. The follow-up survey revealed that respondents interpreted this attribute to be the amount of fish the visiting foreign tourist fishers could catch, rather than the Norwegian resident recreational fishers. In that case, the positive sign of the estimate makes sense, as about $40 \%$ of the respondents do think that tourism fishing reduces local stocks of fish (see Table 3). Respondents who engaged in recreational fishing reported their average catch to be $9.4 \mathrm{~kg}$ per trip (median $5.5 \mathrm{~kg}$ ). In the survey, average recreational catches per fishing day was assumed to be $15 \mathrm{~kg}$, which was reduced by $5 \mathrm{~kg}$ (status quo), 2 $\mathrm{kg}$ or $0 \mathrm{~kg}$ to generate levels for the "recreational catch" attribute. Thus, even with a reduction in catches of $5 \mathrm{~kg}$, most recreational fishers would still be reaching a level of catch when they go fishing. A further robustness analysis of respondents indicating catches over $15 \mathrm{~kg}$ per fishing day ( 23 respondents, making 184 choices) was carried out. There were no changes in sign and significance of the other attribute coefficients, and the coefficient for catches were still positive in all models. However, this result was insignificant in models 1 and 3 , and only significant at the $10 \%$ level in model 2 (t-ratio of 1.92), with insignificant standard deviations in all models. This may indicate indifference, or attribute non-attendance, towards the "recreational catches" attribute. It is possible that when thinking of the value of recreational fishing, a significant proportion of the value for respondents may lie in taking part in the activity, with actual catches being of minor importance.

\subsection{Variation in preferences across rural and urban respondents}

From the focus groups, we know that people in urban and rural areas view economic development differently, with urban residents being more critical of increases in commercial facilities along the coast. Splitting the sample into two subsets yielded one urban subset containing 243 respondents from the largest towns in the region, ${ }^{3}$ and one rural subset encompassing the remaining 275 respondents. Again, the sample is broadly representative as urban municipalities contain $43 \%$ of the total population of Arctic Norway, and $46 \%$ of the respondents. Concentrating on variation in preferences for economic development we use model 2 , which has the highest number of significant development attributes.

\footnotetext{
${ }^{3}$ These towns are Bod $\varnothing$, Narvik, Harstad, Troms $\varnothing$, Hammerfest, Alta, Kirkenes, Vard $\varnothing$ and Vads $\varnothing$.
} 
For each attribute and each subset, we derive unconditional marginal mean WTPs for each of the attributes and their $95 \% \mathrm{Cl}$, all measured in USD. The estimated marginal mean WTPs for the two subsets are compared using the Welch's t-test. The results are given in Table 6.

RURAL SUB-SAMPLE
URBAN SUB-SAMPLE
TEST

STATISTIC

\begin{tabular}{l|lllll}
\hline ATTRIBUTE & WTP & $95 \% \mathrm{Cl}$ & WTP & $95 \% \mathrm{Cl}$ & \\
ONLY & -51.4 & $(-53.4,-49.5)$ & -5.0 & $(-7.3,-2.5)$ & 27.77 \\
$\begin{array}{l}\text { AQUACULTURE } \\
\text { ONLY MARINE }\end{array}$ & -62.8 & $(-63.5,-62.1)$ & -5.6 & $(-5.7,-5.6)$ & 155.2 \\
$\begin{array}{l}\text { FISHING } \\
\text { TOURISM }\end{array}$ & & & & & \\
LITTER & -41.3 & $(-43.4,-39.2)$ & -228.1 & $(-236.3,-$ & -46.13 \\
& & & & $219.9)$ & \\
RECREATIONAL & 190.6 & $(190.0$, & 111.5 & $(111.3$, & 598.44 \\
CATCHES & & $191.1)$ & & $112.1)$ & \\
NEW JOBS & 202.4 & $(201.9$, & 140.0 & $(137.9$, & 112.34 \\
& & $203.0)$ & & $142.0)$ & \\
& & & & &
\end{tabular}

Table 6 Mean marginal WTP and 95\% confidence intervals for the mean marginal WTP, model 2, rural and urban sub-samples, USD. All estimates are significant at $1 \%$ level.

The results in Table 6 clearly identify the main differences between the rural and urban respondents' stated preferences. While preventing more litter on the beaches is the single most important attribute for urban respondents, rural respondents are willing to pay far less for preventing more litter on the beaches, but considerable amounts for new jobs and reduction in recreational catches of fish. On the other hand, urban respondents have a low willingness to pay for seeing both industries along the coast instead of only one industry.

As expected, the confidence intervals $(\mathrm{Cl})$ for the two sub-samples are lower for all attributes compared to the $\mathrm{Cls}$ of the merged dataset. The one estimate with a relatively wide $\mathrm{Cl}$ is for the attribute "only aquaculture" in the urban sub-sample. This indicates that the impact fish farms have on the view is more disputed among the urban respondents than is the impact tourism facilities have on the view. Rural respondents, on the other hand, have homogenous preferences for seeing both commercial activities along the coast. 
To test whether people who are more recreationally active in the CZ have different preferences for preserving these areas from economic development each attribute was interacted with a numeric variable indicating the number of times a person performed recreational activities during the summer season. This did not give any significant results in terms of model specification and statistical significance of the interaction terms. One reason may be the heterogeneous character of the activities listed in the questionnaire, where some are easy to take part in such as walking, while others, like diving need more preparation or equipment. One could therefore expect that a "walker" may perform her/his activity more often than a diver, which is supported by the data. However, there is no reason to assume that the diver is less (or more) concerned about environmental or development attributes of the CZ. As an alternative, we distinguished between recreationalists and nonrecreationalists by interacting each attribute with a dummy, taking the value 1 if the person has been recreationally active in the $\mathrm{CZ}$ at least once during the summer season and zero otherwise. Somewhat surprisingly given the sample size, 25 respondents with a total of 186 choices, the interaction dummy was found to be significant in all three models. The interaction term was positive for the two environmental attributes, litter and recreational catches, indicating that people who are active in the coastal zone preferred, or rather accepted, higher increases in litter and higher reductions in recreational fish harvest. Furthermore, being recreationally active increases the probability that a person prefers to see more commercial facilities along the coast. Hence, recreationalists tend to prefer to see more rather than less commercial facilities along the coast and they are less concerned about environmental quality deterioration compared to non-recreationalists. Only for the job attribute and the alternative specific constant (ASC) the interaction term is not statistically significant, indicating that recreationally active people do not distinguish from non-recreationalists when it comes to preferences for new jobs and stricter regulation of commercial activities along the coast.

In order to test whether the access to clean beaches affected respondents' preferences for stricter management, respondents were asked to assess the quality of the CZ location where they currently perform recreational activities and how much litter they found there (see Table 2 for the results). Each of the attributes were interacted with a discrete variable representing the Likert scale numbers for level of garbage and environmental quality (see Table 2). Only the interaction variable measuring the amount of litter on the beaches and the ASC were significant. The negative sign on the coefficient indicates that the more litter people find on the beaches the less likely it is that they will choose the BAU alternative and the more likely that they will choose stricter regulations of commercial activities in the CZ with an associated payment amount. This result was valid for all models 1-3.

The quality of these recreational locations was measured in terms of how intact or undeveloped the area is, with lower Likert scale numbers indicating perceptions of less developed beaches. We found three significant 
interaction variables; the ASC for the BAU, fish catches and jobs, and all interactions were negative. This was the case in all three models. The negative interaction with the ASC for the BAU alternative is explained above. The negative interaction with the recreational fish catches attribute indicates that respondents using more developed beaches are less likely to choose alternatives with high reduction in catches. In other words, people who experience developed recreational areas prefer lower reduction in catches than people experiencing less developed areas. Finally, the negative interaction with the job attribute indicates that people perceiving a more developed CZ prefer alternatives with lower number of jobs associated with less commercial development.

\subsection{Discussion of results}

In the wake of the recent decline in the Norwegian oil and gas industry, politicians and other decision makers in Norway have emphasised other marine industries as a priority for future economic growth (MTIF, 2015). Fish farming and marine fishing tourism are the two most prominent industries expected to increase in the $\mathrm{CZ}$ of Arctic Norway the coming years. Simultaneously, recreational activity in the $\mathrm{CZ}$ is an integral part of life for most people living in Arctic Norway. Hence, user conflicts may increase in the $C Z$, which require cunning management plans. The present study aims at informing such management. Although people on average prefer more to less commercial activity along the coast, they also clearly prefer management alternatives with stricter environmental regulations. One reason is to avoid increased amounts of litter on the beaches. Such preferences for environmental concerns by people accepting industrial development are also found in Mallawaarachchi et al (2001). They elicited preferences for protection of natural vegetation in areas suitable for cane production by the local community in Herbert, Australia. Local inhabitants exhibited a preference for the extra income generated by the sugar cane industry, but their unit WTP for protecting teatree woodlands and local wetlands overshadowed their WTP of increased industrial activity. Mallawaarachchi et al $(200, p .313)$ conclude that their results indicate that local residents, who benefit significantly from the sugar industry, are willing to pay for environmental protection. This is in concert with our results, showing that people are willing to pay for reducing the amount of litter on the beaches as well as for stricter environmental regulation than currently employed. Mallawaarachchi et al (2001) also found that the WTP for wetland protection is higher than the WTP for teatree protection, which is explained by the fact that local people make regular use of the wetlands for recreation. This is contrary to our study. Instead, we find that people performing recreational activities in the $\mathrm{CZ}$ were willing to accept more litter on the beaches, larger reductions in recreational fish catches, and exhibited a higher preference for seeing commercial facilities along the coast. One reason for the divergence in results from the two surveys may be that our study region is less developed and more sparsely populated. At the time of the study in Herbert, the sugar industry had been expanding at a rather fast pace the past 10 years, and during the last $15-20$ years $5 \%$ of the total land area had been cleared. In Arctic Norway, on the other hand, the relatively low level of commercial activities taking place in the $\mathrm{CZ}$, may make some increase in the presence of people and activities along the coast 
attractive to many recreationalists. Equally, those more actively participating in recreation on the coast are likely to be those most aware (or rather have more realistically grounded perceptions) of the current environmental quality. Thus, lower WTP for a percentage change may in fact relate to their perceptions of a "better" starting point. In one focus group, people mentioned that for some recreational activities, like kayaking, the presence of facilities along the coast also represents increased safety. We interpret these results as supporting the viewpoint that recreational and commercial activities can co-exist along the Arctic Norwegian coast, and that there is sufficient space for the expansion of both. However, concentrating on inhabitants utilizing coastal locations, which have been developed commercially, they preferred lower reductions in recreational catches and also display less support for an increase in the number of commercial facilities along the coast. This results seems to be in line with the results from Mallawaarachchi et al (2001).

The Mallawaarachchi et al (2001) study did not distinguish between various groups of the population in their survey. Rambonilaza and Dachary-Bernard (2007), in their study of landscape preferences in Brittany (France), distinguished between residents and visitors and showed that respondents across both groups were willing to pay for programs to change the present landscape. Landscape preferences varied across the two groups, but while residents showed relatively homogenous preferences, visitors' preferences varied depending on whether they originated from rural or urban areas. We find the same divide in preferences across urban and rural residents when it comes to the coastal landscape (seascape).

While there are respondents with both positive and negative preferences for the presence of fish farms, there is no such structural heterogeneity relating to the presence of tourism facilities. On the other hand, this result may also reflect the present debate in Norway on the development of marine industries. While there is an ongoing media debate on the future expansion of the aquaculture industry, for example pros and cons of land-based facilities, there is less discussion about the marine fishing tourism industry. A few years back, there was a heated media debate on the catches of marine tourist anglers, which eventually ended with the introduction of a limit of $15 \mathrm{~kg}$ of fish filet for foreign tourist fishers to take out of the country (Borch, 2009). Hence, we can speculate whether stated preferences on the further development of marine fishing tourism may had been more diverse if the survey had been conducted before the introduction of this "export limit".

The positive preference for seeing both fish farms and tourism facilities along the coast is in line with results from the Kaltenborn et al. (2017) survey in the Lofoten-Vesteraalen area of Arctic Norway. In this survey all marine industries in Norway were listed, and respondents were asked to indicate those with the largest potential for creating conflict. While the gas and oil industry was mentioned most frequently, i.e. by $50-60 \%$ of the respondents, less than $5 \%$ listed coastal tourism and aquaculture. Other large conflict issues were the development of infrastructure such as roads and airports, organizational matters (like merging several small 
municipalities into larger ones) and the individual transferable quota (ITQ) system implemented in commercial fisheries. Hence, including industries other than tourism and aquaculture in the survey, e.g. oil and gas exploration, may have given different results for the "industrial impact on views" attribute.

Contrary to previous DCE surveys combining environmental and economic attributes (Lockwood et al, 1994; Morrison et al 1999, Blamey et al, 2000), we show that peoples' WTP for new jobs on average is higher, compared to the WTP for environmental attributes. Also, the preferences for the job attribute were relatively homogenous across the sample, with an insignificant standard deviation. This result may indicate that people in Arctic Norway perceive the region to be relatively pristine but with sufficient space for both private recreation and commercial expansions. This said, the results presented should be interpreted with care. For instance, under what conditions will people along the coast of Arctic Norway welcome industrial expansions? This study showed that people put a strong emphasis on environmental regulations. Thus, while the respondents are positive towards industrial expansion, they are not necessarily willing to trade off environmental health and they want strong regulations of the industries. What this study does not capture, among other factors, is whether people prefer industrial expansions to be concentrated to certain areas in order to leave other coastal areas undisturbed for recreational activities, or do they like industrial expansion to be less concentrated but more widespread? And how does this influence their choices in choice experiments like ours? These are questions left for future studies, which should be designed to better uncover the motives for people's choices and have a more detailed treatment of the spatial dimension of coastal development.

\section{$5 \quad$ Conclusions}

Based on the survey presented in this paper, the message to policy makers is that, at present, inhabitants in Arctic Norway support economic development in the form of expansion in the aquaculture and marine fishing tourism industries. This support is more pronounced in rural areas and smaller towns, while people in the most urbanised areas have far lower preferences for seeing more commercial activities along the coast. Hence, policy makers should be more reluctant when it comes to industrial expansion in the vicinity of larger towns and cities. However, there is a clear and substantial positive preference for new jobs, which indicates that commercial activities must be allowed to expand to some degree also in more urbanised areas.

Simultaneously, the very clear preference for stricter regulations of commercial activities and for preventing more marine debris, indicate that industrial expansions must take place under strict regulations, and stricter than the present regulations. Regulations that prevent littering of beaches seems particularly important to people. People in Arctic Norway do not seem to be very concerned about lower recreational fish catches, at least not from a level of $15 \mathrm{~kg}$ per fishing day. Hence, policy makers do not need to be reluctant to introduce limitations on recreational 
catches in order to preserve local fish stocks, at least not if such limitations still allows people to fish 10-12 kg per day.

It would be of interest to understand more of the rationale behind the elicited stated preferences, i.e. on what conditions does the inhabitants in Arctic Norway welcome commercial expansions? Also, it would be of interest to implement similar surveys for other parts of Norway (with more commercial developments) and in other Arctic regions to test how transferable our results are to other geographical areas. These are also topics for future research.

\section{Appendix:}

\begin{tabular}{|c|c|c|c|}
\hline Attribute & Regulations as of today (BAU) & Stricter regulations $\mathrm{A}$ & Stricter regulations B \\
\hline $\begin{array}{l}\text { Industrial } \\
\text { impact on } \\
\text { views }\end{array}$ & $\begin{array}{l}\text { Fish farms and tourism } \\
\text { facilities changes the seascape }\end{array}$ & $\begin{array}{l}\text { Only tourism facilities changes } \\
\text { the seascape }\end{array}$ & $\begin{array}{l}\text { Only fish farms changes the } \\
\text { seascape }\end{array}$ \\
\hline $\begin{array}{l}\text { New jobs in } \\
\text { Arctic } \\
\text { Norway }\end{array}$ & 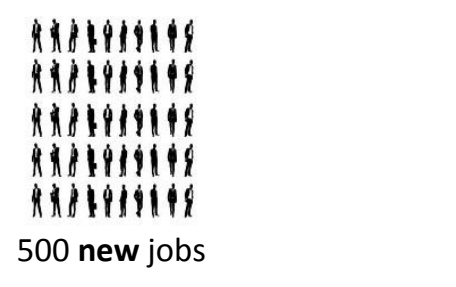 & 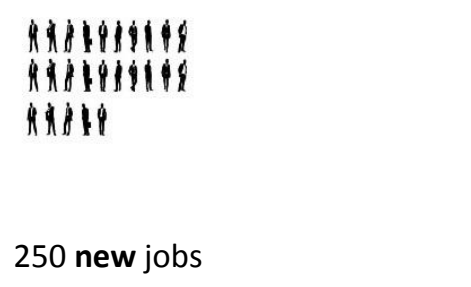 & 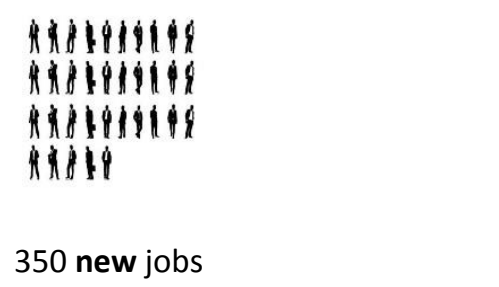 \\
\hline Beach litter & $50 \%$ increase in beach litter & No increase in beach litter & $25 \%$ increase in beach litter \\
\hline $\begin{array}{l}\text { Recreational } \\
\text { catches } \\
\text { from boat }\end{array}$ & $\begin{array}{l}5 \text { kg less harvest per day of } \\
\text { fishing from boat }\end{array}$ & $\begin{array}{l}\text { No reduction in harvest per day } \\
\text { of fishing from boat }\end{array}$ & 2 kg less harvest per day of fishing \\
\hline
\end{tabular}




\begin{tabular}{|c|c|c|c|}
\hline $\begin{array}{l}\text { Increase in } \\
\text { tax }\end{array}$ & 0 & 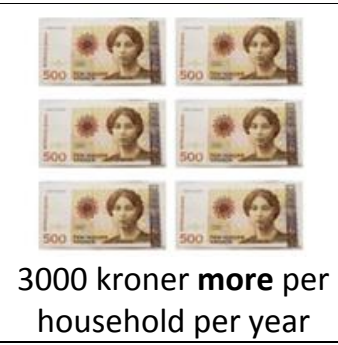 & $\begin{array}{c}1000 \text { kroner more per household } \\
\text { per year }\end{array}$ \\
\hline $\begin{array}{l}\text { What do } \\
\text { you prefer? }\end{array}$ & $\square$ & $\square$ & $\square$ \\
\hline
\end{tabular}

Figure A1 Constructed Choice card for the DCE, translated from Norwegian. This represents one of a set of 8 cards. Each card contains the same "Regulations as of today" (BAU) case and two "payment on" options (A and B) which are made up of some combination of the attributes outlined in Table A determined by an efficient design methodology.

SUMMER $\quad$ WINTER

\begin{tabular}{l|llllllll}
\hline $\begin{array}{l}\text { Number of } \\
\text { times } \\
\text { performing } \\
\text { the activity }\end{array}$ & 0 & $1-3$ & $>3$ & $N$ & 0 & $1-3$ & $>3$ & $N$ \\
FISH & 42 & 26 & 32 & 433 & 82 & 9 & 9 & 419 \\
BOAT & 36 & 30 & 34 & 435 & 80 & 13 & 7 & 415 \\
KAYAK & 90 & 5 & 5 & 391 & 98 & 1 & 1 & 397 \\
DIVE & 97 & 1.5 & 1.5 & 385 & 99 & 0 & 1 & 400 \\
SWIM & 64 & 24 & 12 & 401 & 96 & 3.5 & 0.5 & 400 \\
CAMP & 72 & 20 & 8 & 402 & 95 & 4 & 1 & 397 \\
GRILL & 21 & 28 & 51 & 441 & 67 & 21 & 12 & 412 \\
WALK & 8 & 11 & 81 & 476 & 28 & 17 & 55 & 453 \\
CYCLE & 58 & 13 & 29 & 407 & 90 & 2 & 8 & 400 \\
PHOTO & 43 & 14 & 43 & 411 & 55 & 14 & 31 & 419 \\
PIER & 32 & 18 & 50 & 431 & 49 & 18 & 33 & 429 \\
BEACH & 16 & 19 & 65 & 458 & 57 & 17 & 26 & 423 \\
OTHER & 86 & 2 & 12 & 214 & 92 & 0.5 & 7.5 & 231 \\
& & & & & & & & \\
\hline
\end{tabular}

*The percentages are based on the respondents that answered this question. For all activities, the number of observations is lower than the total of 518 respondents. As it is likely, but not certain, that non-respondents to this question did not perform any of the activities, the percentages in the Table might be overestimates of the percentage of the population performing these recreational activities one time or more during winter and summer.

Table A1 The percent of respondents performing different recreational activities 0, 1-3, and more than 3 times in the summer (May-September) and winter (October-April) months, respectively, during the last 12 months. 



\section{Acknowledgement}

The results presented in this paper have been generated as part of the project "Non-commercial values attached to marine resources in the coastal zone". Professor Margrethe Aanesen from UiT-The Arctic University of Norway has been the project leader, and the project has been financed by the Research Council of Norway, program "the Ocean and the Coast", grant \#225228. We appreciate the funding enabling this research, and we would like to thank all focus group participants and others that has provided information to the project. We would also like to thank Professor Claire Armstrong at UiT-The Arctic University of Norway for fruitful discussions on valuation studies of marine ecosystem services. 


\section{References}

Abate, T.G., R.Nielsen, M.Nielsen, 2017. «Agency rivalry in a shared regulatory space and its impacts on social welfare: the case of aquaculture regulation". Aquaculture economics \& management, http://dx.doi.org/10.1080/13657305.2017.1334243

Blamey, R.K., M.S.Common and J.Quiggin. 1996. "Respondents to contingent valuation surveys: Consumers or Citizens?" Australian Journal of Agricultural Economics 39 (3): 263-288

Blamey, R.K., J.W.Bennett, J.J.Louviere, M.D.Morrison, J.C.Rolfe. 2000. "A test of policy labels in environmental choice modelling studies". Ecological economics 32( ): 269-286

Bennett, J.W., R.K.Blamey (eds). 2001. The choice modelling approach to environmental valuation. Cheltenham, UK

Borch, T. 2009. "Contested Commercialization. Marin Fishing Tourism in Norway." MAST Marine Studies 8 (1): $33-$ 51

Borch, T. (2010). Tangled Lines in New Zealand's Quota Management System: the Process of Including Recreational Fisheries. Marine Policy 34 (3): 655-662.

Borch, T., M. Moilanen and F. Olsen. 2011. Marine fishing tourism in Norway: Structure and Economic Effects. $\varnothing$ konomisk fiskeriforskning 21 (1): 1-17.

Brattland, C., E.Eythorsson, 2016. Fiskesløyfa: Spildrafiskernes driftsformerog oppdrettsaktiviteten, Ottar 312: 2333 (only in Norwegian)

ChoiceMetrics, 2014. Ngene 1.1.2: User Manual and Reference Guide.

Directorate of Fisheries. 2016. Aquaculturestatistics Fiskeridirektoratet (Norwegian directorate of Fisheries). 2016. Akvakulturstatistikk; http://www.fiskeridir.no/Akvakultur/Statistikk-akvakultur/Akvakulturstatistikktidsserier ; http://www.fiskeridir.no/Akvakultur/Statistikk-akvakultur/Akvakulturstatistikk-tidsserier

CMC (2017), CMC choice modelling code for R, Choice Modelling Centre, University of Leeds, www.cmc.leeds.ac.uk.

Ferter, K., T. Borch, J. Kolding and J. H. Vølstad. 2013. Angler behavior and implications for management - Catchand-Release among marine angling tourists in Norway. Fisheries Management and Ecology. 20 (2-3): 137-147.

Fletcher, R., Baulcumb, C., Hall, C. and Hussain, S. 2014. "Revealing marine cultural ecosystem services in the Black Sea." Marine policy 50:151-161.

Freeman, A.M.III, J.A.Herriges, C.L.Kling (eds). 2014. The measurement of environmental and resource values. RFF Press, Taylor\&Francis

Hanley, N., W.S.Shaw, R.E.Wright. 2003. The new economics of outdoor recreation. Edward Elgar Publishing Ltd. Hanley, N., E.Barbier. 2009. Pricing Nature: Cost-benefit Analysis and Environmental Policy, Edward Elgar Hensher, D.A., J.M.Rose and W.H.Greene. 2007. Applied Choice Analysis. A primer. Cambridge University Press 
Hensher, D.A., Rose, J.M., Greene, W.H., 2012. Inferrong attribute non-attendance from stated choice data: implications for willingness to pay estimates and a warning for stated choice experiment design. Transportation, 39: 235-245.

Hersoug, B., J.P.Johnsen (eds). 2012. Kampen om plass på kysten. Interesser og utviklingstrekk i kystsoneplanleggingen. Universitetsforlaget, Oslo

Jentoft, S., A.Buanes. 2005. "Challenges and myths in the Norwegian Coastal Zone Management" Coastal management 33: 153-167

Kaltenborn, B., Linnell, J.D.C., Thomassen, J., Lindhjem, H. 2017. Complacency or resilience? Perceptions of environmental and social change in Lofoten and Vesterålen in northern Norway. Ocean and Coastal Management, 138: $29-37$

Kartverket. 2016. Arealstatistikk for Norge 2016 (The Norwegian mapping authority, Area statistics for Norway 2016)

Lockwood, M., J.Loomis, T.DeLacey. 1994. "The relative unimportance of a non-market willingness to pay for timber harvesting". Ecological Economics 9 ( ): 145-152

MacFadden, D. 1974. "Conditional logit analysis of qualitative choice behavior" In P.Zarembka (ed) Frontiers of Econometrics, New York: Academic Press; pp 105-142

Mallawaarachchi, T., R.K.Blamey, M.D.Morrison, A.K.L.Johnson, J.W.Bennett. 2001. Community values for environmental protection in a cane farming catchment in Northern Australia: A choice modelling study. Journal of Environmental Management 62 83), 301-316

Meeren, G.v.d., 2009. Det marine miljøet I Lofoten - delutredning for arbeidet med Lofotensom kandidat til UNESCO's liste over verdens natur- og kulturarv (The marine environment in Lofoten - part of a report assessing the Lofoten Islands as a candidate for UNESCO's world heritage list - only in Norwegian), Institute of Marine Research (IMR), Bergen, Norway

MTIF (Ministry of Trade, Industry and Fisheries). 2015. "Maritime options - blue growth for a blue future" The maritime strategy for the Norwegian Government, publication code W-0004 B

Morrison, M., J.W.Bennett, R.K.Blamey. 1999. "Valuing improved wetland quality using choice modelling" Water Resources Research 35: 2805-2814

Navrud, S. (ed).1992. Pricing the European Environment. Scandinavian University Press

Nilsson, M., A.Jordan, J.Turnpenny, J.Hertin, B.Nykvist, D.Russel. 2008. "The use and non-use of policy appraisal tools in public policy making: an analysis of three European countries and the European Union" Policy Science, 41 (): 335-355

Primavera, J.H., 2006. Overcoming the Impacts of Aquaculture on the Coastal Zone. Ocean and Coastal Managment 49, 531-545

Rambonilaza, M, Dachary-Bernanrd, J., 2007. Land-use planning and public rpeferences: What can we learn from choice experiment method? Landscape and urban planning 83, 318-326

Rosenberger, Randall S. 2016. Recreation Use Values Database - Summary. College of Forestry, Oregon State University, Corvallis, USA. http://recvaluation.forestry.oregonstate.edu/ 
Scarpa, R., M.Thiene. 2003. "Destination choice models for rock climbing in the northeastern Alps: a latent class approach based on intensity of preferences". Land Economics, 81 ( ): 426-444

Schlapfer, F., B. Fischhoff. 2012. "Task familiarity and contextual cues predict hypothetical bias in a meta-analysis of stated preference studies". Ecological Economics 81, 44-47

Train, K.E. 2009. "Discrete Choice methods with simulation" $2^{\text {nd }}$ ed. Cambridge University Press

Tromsø municipality. 2015. Kystplan Tromsøregionen. Kommuneplanens arealdel for sjøområdene (only in Norwegian).

Vølstad, J. H., K. Korsbrekke, K. H. Nedreaas, M. Nilsen, G. N. Nilsson, M. Pennington, S. Subbey and R. Wienerroither. 2011. Probability-based surveying using self-sampling to estimate catch and effort in Norway's coastal tourist fishery. ICES Journal of Marine Science 68: 1785-1791.

Våge, O.F., 2015. Mosjon, friluftsliv og kulturaktiviteter. SSB-rapport 15. Statistics Norway, Oslo (only in Norwegian)

Whitmarsh, D., Wattage, P. 2006. Public Attitudes Towards the Environmental Impact of Salmon Aquaculture in Scotland. European Environment 16, 108-121 